\title{
A 5 year study of leprosy patients in a tertiary care centre
}

\author{
Rashmi Mahajan ${ }^{1}$, Kishan Ninama $^{2, *}$, Varun Jain ${ }^{3}$, F.E Bilimoria ${ }^{4}$, Som Lakhani ${ }^{5}$ \\ ${ }^{1,2}$ Associate Professor, ${ }^{3}$ PG Resident, ${ }^{4}$ Professor, ${ }^{5}$ Assistant Professor, Dept. of Skin \& VD, S.B.K.S. Medical Institute \& \\ Research Centre Sumandeep Vidyapeeth University, Gujarat, India
}

*Corresponding Author:

Email: drkishanninama.dermatologist@gmail.com

\begin{abstract}
Introduction: The implementation of MDT has resulted in bringing the national prevalence down to elimination of less than 1/10,000 in December 2005 and even further down to 0.66/10,000 in 2016. This study highlights the demographic data, clinical features, reactions and deformities in leprosy patients; thereby bringing to light the public health importance of this simmering disease.

Materials and Methods: It is a retrospective study of leprosy patients in S.B.K.S Medical Institute \& Research Centre, Piparia, Waghodia, Vadodara. Study-subjects included patients with leprosy who presented at dermatology OPD from 1 st April 2013 \& till 31st march 2018. Statistical analysis was done using percentages and tables.

Results: There were a total of 329 cases. 10 patients (3.03\%) were in pediatric age group. Male preponderance with M:F ratio is 2.2:1. Family history was seen in 8 patients $(2.43 \%)$. $69.91 \%$ patients were from rural area. Clinically $8.38 \%$ patients had single patch, $90.57 \%$ had nerve involvement. The most common type was borderline tuberculoid leprosy (33.17\%). Out of these 329 cases, 209 cases had completed the treatment, 89 were on treatment. 31 patients were defaulters.

Conclusion: Inspite of advent of MDT since 1981 and a multipronged approach by the government to eradicate the disease, we still continue to see new and inadequately treated cases; several of them land up in permanent deformities. Our study is only the tip of iceberg as several cases in the interiors of India still go untreated.
\end{abstract}

Keywords: Leprosy, Deformity, Disability, Reactions, Erythema nodosum leprosum.

\section{Introduction}

Leprosy $^{1}$ is a chronic granulomatous infection, principally affecting the skin and peripheral nerves, caused by the obligate intracellular organism Mycobacterium leprae. Leprosy remains a stigmatizing disease.

Multidrug therapy (MDT), however, which cures the infection, has led to the understanding that leprosy can be effectively treated before disability. Although the disease is present throughout the country, the distribution is uneven. After introduction of MDT in the country, the recorded leprosy case load has come down from 57.6 cases per ten thousand population in 1981 to less than one case per 10,000 population at national level in December 2005. ${ }^{2}$ However, the new case detection rate which is an important statistical indicator in National Leprosy Eradication Programme has not shown any significant decline. The general impression among experts is that there were considerable changes in the epidemiological pattern of the disease during the past decade. These changes are reflected by clinical profile of newly detected cases; an increasing proportion of patients diagnosed with few lesions; variations in the proportion of $\mathrm{MB}$ patients and decreasing proportion of patients with irreversible disabilities.

In addition, there were visible changes in the prognosis of the disease during treatment and significant reduction in the risk of becoming disabled. All these changes could be explained by a combination of factors, e.g. the historical trend of the disease; the impact of interventions; the efficacy of antileprosy drugs and the role of improved health services. ${ }^{3}$ Inspite of this, the number of resistant and relapse cases is also on the rise. Through this study, we intend to highlight the demographic data, clinical features, reactions and deformities in leprosy patients; there by bringing to the light the public health importance of this simmering disease.

\section{Materials and Methods}

This was retrospective study conducted in Smt. B.K. Shah medical institute and research centre, Piparia, Vadodara. After getting the Institutional Ethical Committee clearance, records of all leprosy cases were obtained from April 2013 till March 2018. Leprosy cases were searched from the records of Department of Dermatology, Venereology \& Leprosy. All newly diagnosed cases were included in the study. Data was analyzed according to age, sex, type of residence, native state, occupation, type of leprosy, presence or absence of disabilities/deformities. Clinical spectrum of the patients was decided after analyzing the clinical details and results of slit-skin smear examination. Patients were classified as per Ridley Jopling classification and were analyzed for descriptive statistical analysis in which all qualitative data has been presented in percentage form.

\section{Results}

In this study, total of 329 cases were registered and clinically new diagnosed during this study period of 5 years. 
Socio-demographic characteristics: In this study, age of patients ranging between 5 to 80 years of age. Among them, maximum number of cases (99 patients) belong to $21-30$ years $(30.09 \%)$. 10 patients $(3.03 \%)$ were in pediatric age group. There was male preponderance with M:F ratio is 2.2:1. The current study shows leprosy prevalence maximum in farmers followed by labourers $(20.97 \%)$, housewives $(12.46 \%)$, self employed $(8.21 \%)$, teacher $(3.34 \%)$ and student $(3.04 \%)$ (Table 1).

Majority of patients were from rural area (230, $69.91 \%)$. Family history was seen in 8 patients $(2.43 \%)$. Maximum number of patients were from Madhya Pradesh (Table 1).

Table 1

\begin{tabular}{|c|c|c|}
\hline $\begin{array}{c}\text { Socio demographic } \\
\text { data }\end{array}$ & $\begin{array}{l}\text { No of } \\
\text { cases }\end{array}$ & $\begin{array}{c}\text { Percentage } \\
(\%)\end{array}$ \\
\hline \multicolumn{3}{|l|}{ Age Group } \\
\hline$\leq 10$ Years & 3 & $0.91 \%$ \\
\hline 11-20 Years & 13 & $3.95 \%$ \\
\hline 21-30 Years & 99 & $30.09 \%$ \\
\hline 31-40 Years & 72 & $21.88 \%$ \\
\hline 41-50 Years & 85 & $25.84 \%$ \\
\hline 51-60 Years & 34 & $10.33 \%$ \\
\hline$>60$ Years & 23 & $6.99 \%$ \\
\hline \multicolumn{3}{|l|}{ Gender } \\
\hline Male & 226 & $68.69 \%$ \\
\hline Female & 103 & $31.31 \%$ \\
\hline \multicolumn{3}{|l|}{ Occupation } \\
\hline Farmer & 171 & $51.98 \%$ \\
\hline Labourers & 69 & $20.97 \%$ \\
\hline Housewife & 41 & $12.46 \%$ \\
\hline Self employed & 27 & $8.21 \%$ \\
\hline Student & 11 & $3.34 \%$ \\
\hline Teacher & 10 & $3.04 \%$ \\
\hline \multicolumn{3}{|l|}{ Family History } \\
\hline Yes & 8 & $2.43 \%$ \\
\hline No & 321 & $97.57 \%$ \\
\hline
\end{tabular}

Table 2: Geographic distribution

\begin{tabular}{|l|c|c|}
\hline Rural & 230 & $69.91 \%$ \\
\hline Urban & 99 & $30.09 \%$ \\
\hline State & \multicolumn{3}{|l|}{} \\
\hline Gujarat & 94 & $28.57 \%$ \\
\hline MP & 220 & $66.87 \%$ \\
\hline Rajasthan & 15 & $4.56 \%$ \\
\hline
\end{tabular}

Clinical Characteristics: in the current study, leprosy patients presented with skin lesions $(93.92 \%)$, epistaxis (64.13\%), loss of sensation (69.00\%), tingling \& numbness (51.98), slippage of foot wears $(47.42 \%)$, fever (61.40), joint pain $(49.52 \%)$ and bilateral pedal edema (18.84\%) (Table 2) In this study, 309 cases had skin lesions including hypopigmented patches, nodules, erythema nodosum, pigmentary ichthyosis, erythematous plaques and trophic ulcers. There were total of $298(90.57 \%)$ patients with patches. $25(8.38 \%)$ cases had single patch, while other patients had multiple patches along with other signs of leprosy. There were $31(9.42 \%)$ cases with no patch seen over body. 29 cases of lepromatous and histoid leprosy presented with nodular lesions. $168(80.38 \%)$ were type 2 reaction presented with erythema nodosum out of which $8(4.76 \%)$ patients presented with necrotic ENL. All $41(19.62 \%)$ cases of type 1 reactions presented with erythematous plaques and neuritis.

Thirty one $(53.44 \%)$ patients of lepromatous leprosy had concomitant pigmentary ichthyosis and mahogany brown discolouration of skin seen about after 3-4 months of starting treatment.

Slit skin smear was done in all cases. 178 (54.01\%) cases showed smear positive while remaining 151 (45.89\%) cases showed smear negative. Out of all cases which were smear positive 98 were BL, 58 were of LL, 9 were of BB, 4 were of BT \& 9 were histoid. All smears were negative in tuberculoid leprosy. Out of 178 cases of positive slit smear, 105 had 1+, 54 had 2+, 12 had $3+\& 7$ had $4+$ bacteriological index.

Out of all cases, clinically 29 cases were of tuberculoid leprosy $(8.81 \%), 56$ cases were of borderline tuberculoid leprosy (17.02\%), 48 cases were of borderline borderline leprosy (14.59\%), 109 cases were of borderline lepromatous leprosy (33.13\%), 58 cases were of lepromatous leprosy (17.63\%), 9 cases were of histoid leprosy $(2.74 \%)$ and 20 cases were of pure neuritic leprosy $(6.07 \%)$.

In our study, reactions were seen in 209 cases out of which $41(19.62 \%)$ were type 1 reaction and $168(80.38 \%)$ were type 2 reaction. Nerve involvement was seen in leprosy in 297 cases $(90.57 \%)$. Ulnar nerve was most commonly nerve affected.

Deformity: In this study, $34.35 \%$ cases had deformities of face which includes leonine facies, madarosis, ear infiltration \& saddle nose. $34.34 \%$ cases had deformities of hand which includes loss of sensation, claw hand and wasting. $40.11 \%$ cases had deformities of foot which includes loss of sensation, clawed toes, foot drop and plantar ulcers.

Table 3

\begin{tabular}{|l|c|c|}
\hline \multicolumn{1}{|c|}{ Characteristics } & $\begin{array}{c}\text { No of } \\
\text { Cases }\end{array}$ & Percentage (\%) \\
\hline Clinical Features & 298 & 90.57 \\
\hline Skin lesion & 211 & 64.13 \\
\hline Epistaxis & 227 & 69.00 \\
\hline Loss of sensation & 171 & 51.98 \\
\hline Tingling \& numbness & 156 & 47.42 \\
\hline Slippage of footwears & 202 & 61.40 \\
\hline Fever & 163 & 49.54 \\
\hline Joint pain \\
\hline Clinical Diagnosis & 29 & $8.81 \%$ \\
\hline Tuberculoid Leprosy & 56 & $17.02 \%$ \\
\hline Borderline tuberculoid & 56 \\
\hline
\end{tabular}




\begin{tabular}{|l|c|c|}
\hline leprosy & & \\
\hline BB leprosy & 48 & $14.59 \%$ \\
\hline $\begin{array}{l}\text { Borderline lepromatous } \\
\text { leprosy }\end{array}$ & 109 & $33.13 \%$ \\
\hline Lepromatous leprosy & 58 & $17.63 \%$ \\
\hline Histoid leprosy & 9 & $2.74 \%$ \\
\hline Pure neuritic leprosy & 20 & $6.07 \%$ \\
\hline Eye Examination & 240 & $72.95 \%$ \\
\hline Normal & 73 & $22.19 \%$ \\
\hline Diminision of vision & 9 & $2.74 \%$ \\
\hline Cataract & 5 & $1.52 \%$ \\
\hline Corneal opacity & 2 & $0.61 \%$ \\
\hline Lagopthalmos
\end{tabular}

Table 4

\begin{tabular}{|c|c|c|}
\hline Deformities & $\begin{array}{l}\text { No of } \\
\text { Cases }\end{array}$ & Percentage (\%) \\
\hline \multicolumn{3}{|l|}{ Deformities of Face } \\
\hline Normal & 216 & $65.65 \%$ \\
\hline Leonine & 39 & $11.85 \%$ \\
\hline Madarosis & 32 & $9.73 \%$ \\
\hline Ear infiltration & 37 & $11.25 \%$ \\
\hline Saddle Nose & 5 & $1.52 \%$ \\
\hline Total & 329 & $100.00 \%$ \\
\hline \multicolumn{3}{|l|}{ Deformities of Hand } \\
\hline Grade 0 & 221 & $67.17 \%$ \\
\hline Grade 1 & 66 & $20.06 \%$ \\
\hline Grade 2 & 47 & $14.28 \%$ \\
\hline $\begin{array}{l}\text { Claw Hand with } \\
\text { Wasting }\end{array}$ & 34 & \\
\hline Claw hand & 16 & \\
\hline Wasting & 7 & \\
\hline \multicolumn{3}{|l|}{ Deformities of foot } \\
\hline Grade 0 & 197 & $59.87 \%$ \\
\hline Grade 1 & 91 & $27.65 \%$ \\
\hline Grade 2 & 41 & $12.46 \%$ \\
\hline Claw toes & 18 & \\
\hline Plantar ulcers & 10 & \\
\hline Foot Drop & 13 & \\
\hline
\end{tabular}

Fig. 2: Ear lobe infilteration
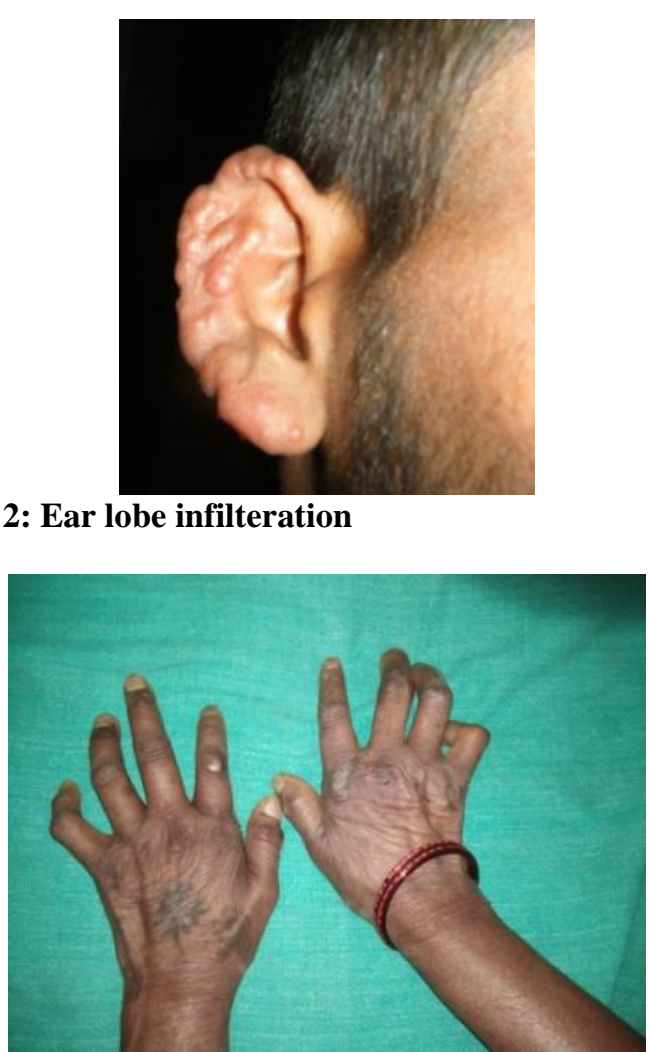

Fig. 3: Claw hand

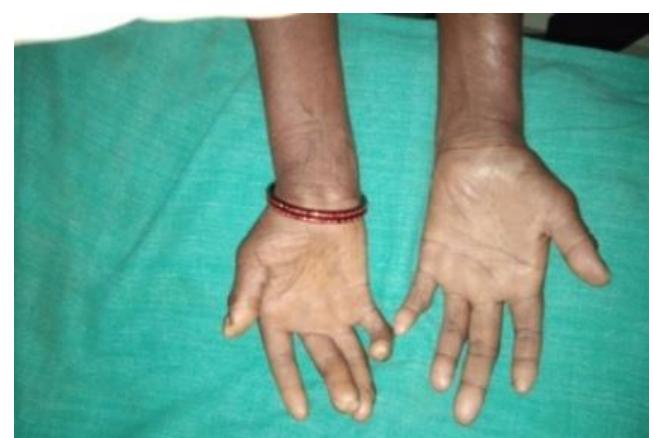

Fig. 4: Wasting

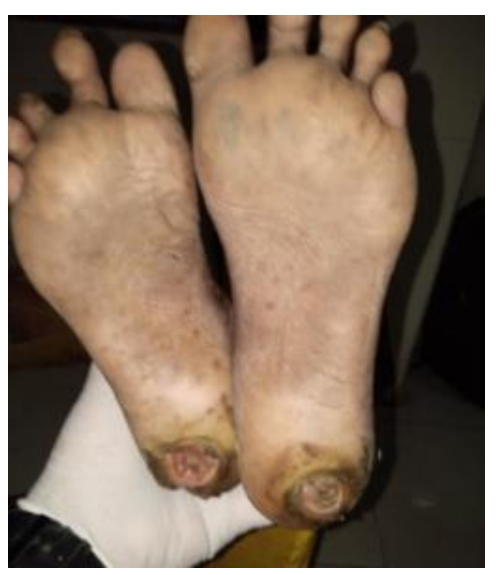

Fig. 5: Trophic ulcer

Fig. 1: Leonine facies, madarosis Saddle nose 


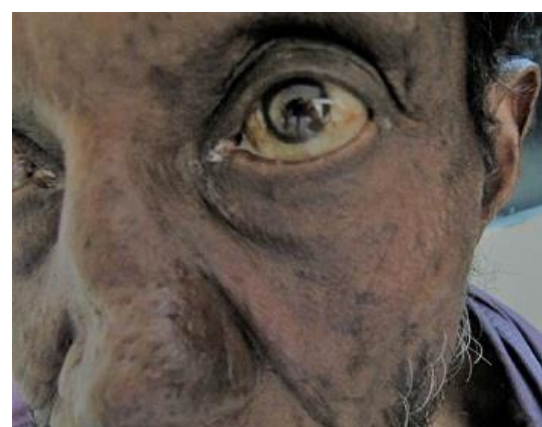

Fig. 6: Cataract

On ophthalmic examination revealed $73(22.19 \%)$ had diminision of vision, $9(2.74 \%)$ had cataract, 5 $(1.52 \%)$ had corneal opacity and $2(0.61 \%)$ had lagopthalmos.

Out of 329 cases, 209 were released from treatment (RFT), 89 were under treatment and remaining 31 were defaulters.

\section{Discussion}

The present strategy of leprosy control is to reduce the load of infection in society by detecting new cases \& providing adequate treatment to patient so as to break the chain of infection. ${ }^{4}$ The implementation of MDT has brought the national prevalence down to less than 1/10,000 in December 2005 and even further down to $0.66 / 10,000$ in $2016 .{ }^{5}$ The WHO launched a 5-year "Global leprosy strategy 2016- 2020' in April 2016 which was titled 'accelerating towards a leprosy free world'. The strategy for years 2016-2020 is given below: ${ }^{5}$

1. To strengthen government ownership, coordination, and partnership

2. To stop leprosy and its complications

3. To stop discrimination and promote inclusion.

Our study was a retrospective one, after analyzing the data of 329 leprosy patients who attended our OPD in period between April 2013 to March 2018. The maximum number of cases (99 patients) belong to 2130 years $(30.09 \%)$. The male: female ratio is $2.2: 1$. In a study conducted by Jindal et ${ }^{6}$ al the maximum number of cases belonged to 21-30 years of age group. A male preponderance was also observed in same study.

Family history was seen in $2.43 \%$ of cases. In a study conducted by Jindal et $\mathrm{al}^{6}$ conjugal leprosy was present in $0.61 \%$ of cases.

Among the types of leprosy our study showed BL Leprosy is most common with $33.13 \%$ followed by LL with $17.63 \%$, BT with $17.02 \%$, BB with $14.59 \%$ and TT with $8.81 \%$. However, in the study conducted in 2009 by Jindal et $\mathrm{al}^{6}$ maximum cases $(33.12 \%)$ were of lepromatous leprosy. In another study conducted in 2016 by Rekam Anusga et al BT was the most common type of leprosy (28.6\%), followed by TT in $26.5 \%$, IDL in $14.3 \%, \mathrm{BB}$ in $12.2 \%$, $\mathrm{LL}$ in $10.2 \%$ and $\mathrm{BL}$ in $8.2 \% .^{7}$ In a study conducted in 2012 by Shivaswamy K N et al
BT was the most common type of leprosy with $38.4 \%$ followed by TT in $17.5 \%$, IDL inn $15.3 \%, \mathrm{BL}$ in $13.1 \%$, LL in $12.6 \%$ and BB in $2.7 \% .^{8}$

In our study, $2.74 \%$ with histoid leprosy which is much higher than study conducted by Kaur I et al in which histoid cases were $1.8 \%{ }^{9}$

In our study, $6.07 \%$ cases with pure neuritic leprosy is higher than in a study conducted by Kuman B et $\mathrm{al}^{10}(4.2 \%)$ and in a study by Mahajan PM et $\mathrm{al}^{11}$ $4.6 \%$ had pure neuritic leprosy.

Slit skin smear was done in all cases. 178 (54.01\%) cases were smear positive while remaining 151 (45.89\%) cases were smear negative. Out of all cases which were smear positive 98 were BL, 58 were of LL, 9 were of BB, 4 were of BT \& 9 were histoid which correlates with study conducted by Bhusan $\mathrm{P}$ et $\mathrm{al}^{12}$ in which 29 cases were from BL and LL, 5 cases were BT.

In our study, reactions were seen in 209 cases out of which 41(19.62\%) were type 1 reaction and $168(80.38 \%)$ were type 2 reaction which correlates with study conducted by Salodkar A D et al ${ }^{13} 30(19.9 \%)$ cases were of type 1 reaction and $121(80.1 \%)$ cases were of type 2 reaction. Severe type 2 reaction with ulceration (Erythema nodosum necroticans) was seen in $4.76 \%$ cases in our study.

In the study, nerve involvement is seen in $90.57 \%$ which is much higher than study from Dakar ${ }^{14}$ which mentions it as $68.49 \%$ cases. $34.35 \%$ cases had various forms of deformities over face. $34.34 \%$ cases had various deformities of hands, $20.06 \%$ cases with grade 1 deformity and $14.28 \%$ cases with grade 2 deformity. $40.11 \%$ cases had various deformities of feet, $27.65 \%$ cases with grade 1 deformity and $12.46 \%$ cases with grade 2 deformity, so prevalence of grade 1 deformity is higher than grade 2 deformity which correlates with study conducted by Jindal et al. ${ }^{6}$ Eye involvement was seen in $26.45 \%$ cases which is higher than study conducted by Jindal et $\mathrm{al}^{6}$ was $17.64 \%$ cases.

\section{Conclusion}

One of the key reasons for the rise in disability is a delay in diagnosis of leprosy and lepra reactions which lead to persistent neuritis and ultimately to disability. There is need for greater awareness about the signs and symptoms of leprosy and reactions among general health care staff as well as in the community to promote self-reporting, as well as early diagnosis and proper management of the disease and its complications in an integrated setting.

\section{References}

1. Park K. Park's Textbook of Preventive \& Social Medicine. Leprosy. Ms. Banarasidas Bhanot Publishers; 22nd Edition. 2013:287-302.

2. Jindal N, Shanker V, Tegta GR, Gupta M, Verma GK. Clinico-epidemiological Trends of Leprosy in Himachal Pradesh: A Five Year Study. Indian J Lepr. 2009;81:1739 . 
3. World Health Organization, Leprosy Elimination Monitoring (LEM).Guidelines for monitors 2000.

4. Rizvi AA, Sharma YK, Dash K, Tyagi N, Yadava R, Sadana D. An epidemiological and clinichistopathological study of leprosy in semi-urban area under Pimpari Chinchwad Municipal Corporation in Pune district of Maharashtra. Med J. Dr. D.Y. Patil University. 2015;8(5):609-13.

5. Rao P N, Suneetha S. Current situation of leprosy in India and its future implications. Indian Dermatol Online J. 2018;9:83-9.

6. Jindal A, Shanker, Tegtha GR, Gupta M. Clinicoepidemiological trends of leprosy in Himachal Pradesh: a five year study. Ind J Lepr. 2009,81:173-179.

7. Anusha Rekam, Jyothijayaraman. A study on clinic histopathological correlation in Hansen's disease. Int J Clin and Biomed Res. 2016;2(1):10-12.

8. Shivswamy K.N, Shyamprasad A.L, Sumathy, T.K et al. Clinical and histopathological correlation In leprosy. Dermatol Online Journal. 2012;18(9):2.

9. Kaur I, Dogra S, De D, Saikia UN. Histoid leprosy: a retrospective study of 40 cases from India. $\mathrm{Br} \mathrm{J}$ Dermatol. 2009;160(2):305-10.

10. Kumar B, Kaur I, Dogra S, Kumaran MS. Pure neuritic leprosy in India: an appraisal. Int J lepr Pther Mycobact Dis. 2004:72(3):284-90.
11. Mahajan PM, Jogaikar DG, Mehta JM. A Study of pure neuritic leprosy: clinical experience. Indian J Lepr. 1996;68(2):137-41.

12. Bhushan P, Sardana K, Koranne RV, Choudhary M et al. Diagnosing multibacillary leprosy: A comparative evaluation of diagnostic accuracy of slit skin smear, bacterial index of granuloma and WHO operational classification. 2008;74(4):322-326.

13. Salodkar AD, Kalla G.A. Clinico-epidemiological study of leprosy in ari north-west Rajasthan, Jodhpur. Indian Journal of Leprosy. 1995,67(2):161-166.

14. Niang SO, Diallo M, Ndiaye M, Diop A, Diatta B.A, Wadih M, Kane A, Dieng MT, Badiane CI.

Epidemiological \& clinicopathologic aspects of leprosy in Dakar; evaluation of 73 new cases. Dermatology Reports. 2011:3(e18):40-2.

How to cite this article: Mahajan R, Ninama K, Jain V, Bilimoria FE, Lakhani S. A 5 year study of leprosy patients in a tertiary care centre. Ind $\mathbf{J}$ Clin Exp Dermatol. 2018;4(3):232-236. 